\title{
EBV-positive diffuse large B-cell lymphoma of the elderly is an aggressive post-germinal center B-cell neoplasm characterized by prominent nuclear factor-kB activation
}

Santiago Montes-Moreno ${ }^{1}$, Lina Odqvist ${ }^{2}$, Julio A Diaz-Perez ${ }^{3}$, Ana Batlle Lopez ${ }^{1}$, Sonia Gonzalez de Villambrosía ${ }^{1}$, Francisco Mazorra ${ }^{1}$, Maria E Castillo ${ }^{2}$, Mar Lopez ${ }^{2}$, Raquel Pajares ${ }^{4}$, Juan F García ${ }^{5}$, Manuela Mollejo ${ }^{6}$, Francisca I Camacho ${ }^{7}$, Carmen Ruiz-Marcellán ${ }^{8}$, Magdalena Adrados ${ }^{9}$, Nazario Ortiz ${ }^{10}$, Renato Franco ${ }^{11}$, Carlos Ortiz-Hidalgo ${ }^{12}$, Ana Suarez-Gauthier ${ }^{13}$, Ken H Young ${ }^{14}$ and Miguel A Piris ${ }^{1}$

${ }^{1}$ Pathology and Hematology Departments, Hospital Universitario Marqués de Valdecilla, IFIMAV, Santander, Spain; ${ }^{2}$ Lymphoma Group, Spanish National Cancer Centre (CNIO), Madrid, Spain; ${ }^{3}$ UCSD Moores Cancer Center, La Joya, CA, USA; ${ }^{4}$ Histology and Immunohistochemistry Unit, Spanish National Cancer Centre (CNIO), Madrid, Spain; ${ }^{5}$ Pathology Department, MD Anderson Clinical Cancer Center, Madrid, Spain; ${ }^{6}$ Pathology Department, Hospital Virgen de la Salud, Toledo, Spain; ${ }^{7}$ Pathology Department, Hospital Universitario de Getafe, Madrid, Spain; ${ }^{8}$ Pathology Department, Hospital Vall d'Hebron, Barcelona, Spain; ${ }^{9}$ Pathology Department, Hospital Clínico Universitario de la Princesa, Madrid, Spain; ${ }^{10}$ Pathology Department, Hospital Santa Rosa, Lima, Peru; ${ }^{11}$ Pathology Department, Instituto di Tumori G Pascale, Napoli, Italy; ${ }^{12}$ Pathology Department, Hospital ABC, Mexico DF, Mexico; ${ }^{13}$ Pathology Department (Laboratorio de Dianas Terapéuticas), Centro Integral Oncológico Clara Campal, Madrid, Spain and ${ }^{14}$ Department of Hematopathology, The University of Texas MD Anderson Cancer Center, Houston, TX, USA

Here, we report a retrospective series of 47 EBV-positive diffuse large B-cell lymphoma associated with advanced age. Histopathology allowed to the identification of different histological patterns: cases with polymorphic diffuse large B-cell lymphoma (29 cases), Hodgkin-like (8 cases) and polymorphic lymphoproliferative disorder-like (9 cases) patterns. One case was purely monomorphic diffuse large B-cell lymphoma. We show that this lymphoma type is a neoplasm with prominent classical and alternative nuclear factor-kB pathway activation in neoplastic cells (79\% of the cases showed nuclear staining for p105/p50, 74\% for p100/p52 and $63 \%$ for both proteins), with higher frequency than that observed in a control series of EBV-negative diffuse large B-cell lymphoma $\left(\chi^{2}<0.001\right)$. Most cases showed an activated phenotype $(95 \%$ non-germinal center (Hans algorithm); $78 \%$ activated B cell (Choi algorithm)). Clonality testing demonstrated $I g H$ and/or $K / K d e / L$ monoclonal rearrangements in $64 \%$ of cases and clonal T-cell populations in $24 \%$ of cases. $C$-MYC (1 case), BCL6 (2 cases) or IgH ( 3 cases) translocations were detected by FISH in $18 \%$ cases. These tumors had a poor overall survival and progression-free survival (the estimated 2-year overall survival was $40 \pm 10 \%$ and the estimated 2-year progression-free survival was $36 \pm 9 \%$ ). Thus, alternative therapies, based on the tumor biology, need to be tested in patients with EBV-positive diffuse large B-cell lymphoma of the elderly. Modern Pathology (2012) 25, 968-982; doi:10.1038/modpathol.2012.52; published online 27 April 2012

Keywords: DLBCL; EBV; elderly; NFkB; non-Hodgkin lymphoma

Correspondence: Dr S Montes-Moreno, MD, Pathology Department, Hospital Universitario Marques de Valdecilla, Universidad de Cantabria, IFIMAV, Avda. Valdecilla no. 25, Santander 39008, Spain.

E-mail: smontes@humv.es

Received 19 November 2011; revised 23 January 2012; accepted 23 January 2012; published online 27 April 2012
EBV-positive diffuse large B-cell lymphoma of the elderly is a diffuse large B-cell lymphoma subtype ${ }^{1}$ that has recently been recognized as a provisional entity among the diffuse large B-cell lymphoma subtypes within the WHO classification. It is defined as a clonal B-cell lymphoid proliferation that occurs in patients older than 50 years without 
any known immunodeficiency or previous lymphoma. Cases of lymphomatoid granulomatosis, infectious mononucleosis or other well-defined disorders (such as plasmablastic lymphoma, primary effusion lymphoma and diffuse large B-cell lymphoma associated with chronic inflammation) that may be EBV-positive are excluded from this category. ${ }^{2}$

This subtype of diffuse large B-cell lymphoma was initially reported as 'senile EBV-associated B-cell lymphoproliferative disorder'. ${ }^{3}$ In recent years, it has been noted that defective immune surveillance for EBV may develop late in life and be associated with the development of EBV-positive B-cell lymphoproliferative disorder in individuals who otherwise have no apparent immune deficiency. ${ }^{1}$ This defective immune surveillance for EBV is associated with immunological deterioration as a result of aging. ${ }^{3-5}$ This reduced immune surveillance could be related, at least in part, to the narrowly focused T-cell repertoire, which has limited functional activity against the EBV infection found in these patients. ${ }^{1,6,7}$

Currently, age-related EBV-positive lymphoproliferative disorder accounts for $8-10 \%$ of diffuse large B-cell lymphoma cases among East Asian patients with no predisposing immunodeficiency; ${ }^{4,8,9}$ however, little information is available about the frequency of this condition in western countries., ${ }^{410-12}$ The largest western series published to date, ${ }^{11}$ including other EBV-positive lymphoproliferative lesions (reactive lymphoid hyperplasia, polymorphic extranodal, polymorphic nodal and diffuse large B-cell lymphoma), demonstrates that the spectrum of EBV-related lesions in western populations is wider than previously expected and mirrors the situation found in Asian countries. In addition, a direct comparison between the prevalence of this particular neoplasm between Mexican and German populations demonstrates that EBVpositive diffuse large B-cell lymphoma of the elderly in a Latin-American (Mexican) population has a similar prevalence, comparable with what has been reported in Asian countries, and in contrast to the low frequency in western populations $(1-3 \%){ }^{12}$

Patients with EBV-positive diffuse large B-cell lymphoma have a worse prognosis than those with EBV-negative diffuse large B-cell lymphoma or EBVpositive classical Hodgkin lymphoma. ${ }^{8,13,14}$ Published studies of clinical series have identified a high risk of treatment failure in these patients. ${ }^{5,8}$ Among the clinical factors that have an impact on patient outcome, only B symptoms and an age of $70+$ years are independently predictive of survival, while the International Prognostic Index score did not seem to separate different risk groups as in conventional EBVnegative diffuse large B-cell lymphomas. ${ }^{9}$

Among the biological features of the tumors that might influence patient survival, it seems clear that EBV positivity is a risk factor. ${ }^{8,9}$ However, other biological risk factors, useful in conventional EBVnegative diffuse large B-cell lymphoma, such as the cell of origin (COO) classification (germinal center
B-cell and activated B-cell-type diffuse large B-cell lymphoma $)^{15-17}$ have not yet been fully investigated in this lymphoma subtype. Furthermore, it was not established in the previously published clinical series whether there was a relationship between EBV infection and the induction of an activated phenotype in diffuse large B-cell lymphoma. ${ }^{8}$

In this paper, we report a study of a retrospective series of 47 age-related EBV-positive diffuse large B-cell lymphoma cases retrieved from our hematopathology consultation files over a 6-year period (2004-2010). We have characterized their clinicopathological features and carried out a detailed immunohistochemical, cytogenetic (fluorescent in situ hybridization) and clonality analysis. We have also examined whether these are correlated with clinical variables. Our results demonstrate that EBV-positive diffuse large B-cell lymphoma of the elderly is an aggressive clonal B-cell neoplasm with frequent activated phenotype that is associated with the activation of both classical and alternative nuclear factor-kB pathways.

\section{Materials and methods}

\section{Histological Review, Immunohistochemical Studies and FISH Analysis}

Spanish National Cancer Center (Centro Nacional de Investigaciones Oncológicas, CNIO) consultation files collected over a 6-year period (2004-2010) were reviewed retrospectively. Search criteria included: patient older than 40 years, absence of other cause of immunosuppression and a diagnosis of EBV-positive diffuse large B-cell lymphoma, EBVpositive polymorphic lymphoproliferative disorder or EBV-positive Hodgkin lymphoma. In all, 92 cases were identified using these criteria, all of which were morphologically and immunohistochemically re-evaluated. Of these, 47 cases were included in our analysis because they met the following inclusion criteria: morphology consistent with a diffuse large B-cell lymphoma with higher cell density and preservation of the B-cell program than the expected in classical Hodgkin lymphoma (defined as moderate-intense CD20 positivity in $>50 \%$ of the neoplastic population), together with positivity for EBV-LMP1 and/or EBV-EBER in large- and intermediate-sized cells. The previous diagnosis in these 47 cases was EBV-positive diffuse large B-cell lymphoma in 28 cases, EBV-positive polymorphic lymphoproliferative disorder in 5 cases and EBVpositive classical Hodgkin lymphoma in 14 cases.

A previously published control series with complete follow-up data of 240 EBV-negative diffuse large B-cell lymphomas uniformly treated with R-CHOP or R-CHOP-like regimens was used for comparison, ${ }^{18}$ in terms of survival analysis. The clinical and phenotypic features of this control series are summarized in Table 1 . In addition, up to $279 \mathrm{EBV}$-negative diffuse large B-cell lymphoma 
Table 1 Clinical features of the control series of EBV-negative diffuse large B-cell lymphoma

\begin{tabular}{lc}
\hline Number of patients & 240 \\
IPI factors & \\
Age (years) & \\
$\quad \leqslant 60$ & 96 \\
$\quad>60$ & 141 \\
Stage & \\
$\quad$ I-II & 98 \\
III-IV & 133 \\
LDH & \\
$\quad$ Low & 84 \\
$\quad$ High & 122 \\
Performance status & \\
$\quad$ Ambulatory (0-1) & 146 \\
$\quad$ Not ambulatory (2-4) & 55 \\
Extranodal site involvement & \\
$\quad \leqslant 1$ site & 153 \\
$\quad>1$ site & 48 \\
$\quad$ & \\
IPI score (number of IPI factors) & 79 \\
Low risk (0, 1) & 49 \\
Low-intermediate risk (2) & 55 \\
High-intermediate risk (3) & 50 \\
High risk (4, 5) & \\
COO classification & No. of cases positive/total \\
$\quad$ no. of cases (\%) \\
\hline GCB* & \\
ABC* & $106 / 232(46 \%)$ \\
\hline
\end{tabular}

Abbreviations: ABC, activated B-cell-like type diffuse large B-cell lymphoma; GCB, germinal center B-cell-type diffuse large B-cell lymphoma; IPI, International Prognostic Index.

*According to Choi's algorithm.

cases were analyzed for immunohistochemical expression in nuclear factor-kB pathway proteins and 324 cases for the COO subclassification based on immunohistochemistry.

One tissue microarray was constructed for extended immunohistochemical and fluorescent in situ hybridization (FISH) analysis of EBV-positive diffuse large B-cell lymphoma cases, following conventional protocols. ${ }^{19}$ Immunohistochemical staining and in situ hybridization (ISH) for EBER was performed following conventional automated protocols (details in Supplementary Information and Table 2). All cases (study and control series) were classified according to the COO using the two currently established immunohistochemical algorithms of Hans and Choi. ${ }^{16,17}$ Immunohistochemical expression of nuclear factor-kB-related proteins p100/p52 and p105/p50 was considered positive only when there was nuclear staining (as a surrogate for the activation of alternative and classical nuclear factor- $\mathrm{kB}$ pathways, respectively).

\section{Clonality Analysis}

Clonality was assayed by conventional methods using DNA extracted from formalin-fixed paraffinembedded tissue. Multiplex PCR to detect clonal
VH-JH rearrangements was performed using standardized Biomed2 primers, as fully described elsewhere. ${ }^{20}$ We analyzed complete rearrangements of IgH (VH FR1-JH, VH FR2-JH, VH FR3-JH), and rearrangements of $\mathrm{IgK}(\mathrm{Vk}-\mathrm{Jk}$ and $\mathrm{Vk} /$ intron-Kde), IgL $(\mathrm{V} \lambda-\mathrm{J} \lambda)$ and TCR (TCRG tube A ( $\gamma \gamma-\mathrm{J} \gamma)$, TCRG tube $\mathrm{B}(\mathrm{V} \gamma-\mathrm{J} \gamma)$, TCRB tube $\mathrm{A}(\mathrm{V} \beta-\mathrm{J} \beta)$, TCRB tube $\mathrm{B}(\mathrm{V} \beta-\mathrm{J} \beta))$.

\section{Western Blot}

Immunoblot analysis of nuclear factor-kB-related protein processing was performed using primary frozen diagnostic samples. Details can be found in Supplementary Information 1.

\section{Clinical Data Recovery and Statistical Analysis}

All 47 cases included in the study were identified from the Spanish National Cancer Center (CNIO) hematopathology consultation files over a 6-year period (2004-2010). Patients were from Latin and Latin-American countries, including Spain (43 cases), Peru (1 case), Mexico (1 case) and Italy (2 cases).

Patients' clinical data were retrieved retrospectively using a standard clinical data sheet that included items on International Prognostic Index scoring at diagnosis, treatment received, response to treatment and follow-up. Overall survival (OS) ${ }^{21}$ was considered as the time from diagnosis to the date of death as a result of any cause, or of last contact. Progression-free survival (PFS) was calculated as the time of diagnosis to the date of progression. Cases were censored on the date the patient was last known to be alive or, for patients dying as a result of causes unrelated to the lymphoma or treatment, the date of death. The Kaplan-Meier method was used to estimate OS and PFS distributions. The log-rank and Breslow tests were used to compare survival distributions among subgroups..$^{22,23}$ The study protocol and sampling procedure were approved by the Carlos III Institutional Review Board. Informed consent was obtained when necessary.

\section{Results}

\section{Pathological Description of EBV-Positive Diffuse Large B-Cell Lymphoma of the Elderly}

The diagnosis was made in nodal locations in 31 cases $(66 \%)$, whereas 16 cases $(34 \%)$ were diagnosed in extranodal locations (see details in Table 3). Hematoxylin-eosin examination showed most cases (46) to be characterized by a total or partial effacement of the tissue architecture by a polymorphic large-cell-rich population of neoplastic cells. Only one case (no. 31) was composed of a neoplastic pure monomorphic immunoblastic large-cell population. In two cases (nos. 29 and 46; Figure 1), a mixed pattern with intermingled polymorphic and monomorphic areas was found. Polymorphic cases were subclassified into three 
subgroups on the basis of the relative proportion of large neoplastic cells and the presence of ReedSternberg-like and Hodgkin-like cells. Thus, 29 cases were considered canonical large B-cell neoplasms (high density of large neoplastic cells and scattered cells with Reed-Sternberg-like and Hodgkin-like features), 8 cases were classified as diffuse large B-cell lymphoma with Hodgkin lymphomalike features (lower density of neoplastic cells with Reed-Sternberg-like and Hodgkin-like features) and 9 cases were considered diffuse large B-cell lymphoma with polymorphic lymphoproliferative disorder-like features (low density of neoplastic cells without Hodgkin lymphoma-like features). Interestingly, one case (no. 11) showed morphological features intermediate between diffuse large B-celllike and Hodgkin-like tumors (Figure 1), consistent with the diagnosis of intermediate Hodgkin lymphoma/diffuse large B-cell lymphoma. The pattern of infiltration of the tissues affected was nodular or vaguely nodular in 29 cases (62\%), while the other $18(38 \%)$ being diffuse. One particular case (no. 14) showed a striking nodular lymphocyte predominant Hodgkin-like morphological pattern of growth with an associated diffuse large B-cell lymphoma component. ${ }^{24}$ This particular case also had a phenotype overlapping with nodular lymphocyte predominant Hodgkin lymphoma, except for the presence of EBVpositive cells, and showed downregulation of BCL6 expression (Figure 1). Geographic necrosis was a prominent feature in 14 cases $(29 \%)$.

Cell by cell, the cases showed striking polymorphism and cellular diversity that varied among the previously defined subgroups (large B-cell, Hodgkin lymphoma-like and polymorphic lymphoproliferative disorder-like). Hodgkin-like tumors were characterized by the presence of Reed-Sternberg- and Hodgkin-like scattered cells in a relatively paucicellular neoplastic infiltrate. An evident degree of immunoblastic and plasmacytoid differentiation was found in both large B-cell-like and polymorphic lymphoproliferative disorder-like cases, although this was rare in Hodgkin lymphoma-like tumors $\left(\chi^{2}\right.$ test: $P<0.05$ ) (Figure 1 ). $\mathrm{K}$ and $\lambda$ immunostains were performed in 29 cases. Of these, 22 cases showed light-chain restriction (13 were K-restricted and 9 were $\lambda$-restricted). Five cases had strong unspecific background staining and in two cases it was not evident as a single, light-chain predominance. A peculiar feature found in 11 cases (23\%) was the presence of abortive 'germinal center-like' structures composed of large neoplastic cells, follicular dendritic cells and small lymphocytes (no. 29-1) (Figure 1).

The microenvironmental compartment was commonly composed of small lymphocytes and plasma cells in varying proportions. In 12 cases, the presence of histiocytes was evident, but only in one case (no. 36) were poorly defined epithelioid granulomas found. The absence of a polymorphonuclear inflammatory infiltrate was the rule for almost all the cases. Only two cases (nos. 39 and 44) showed scattered eosinophils in the cellular background. The bone marrow biopsy was examined in two cases (nos. 23 and 26). The pattern of infiltration in these cases consisted of a multifocal interstitial infiltration by a polymorphic Hodgkin-like neoplastic population (Figure 1).

Table 2 Details of immunohistochemical staining products and procedures

\begin{tabular}{|c|c|c|c|c|}
\hline Antibody & Clone & Source & $\begin{array}{l}\text { Antigen retrieval/visualization } \\
\text { method }\end{array}$ & Dilution \\
\hline CD20 & L26 & DAKO, Glostrup, Denmark & EDTA $1 \mathrm{mM} \mathrm{pH} \mathrm{9/FLEX} \mathrm{DAKO}$ & $1 / 50$ \\
\hline GCET1 & RAM & CNIO, Madrid, Spain & $\begin{array}{l}\text { EDTA } 1 \mathrm{mM} \text { pH } 8 / \text { Novolink } \\
\text { (Novocastra) }\end{array}$ & 174 \\
\hline MUM1/IRF4 & Polyclonal goat & $\begin{array}{l}\text { Santa Cruz Biotechnology, Santa } \\
\text { Cruz, CA, USA }\end{array}$ & Citrate $10 \mathrm{mM}$ pH 6.5/FLEX (DAKO) & $1 / 250$ \\
\hline CD10 & $56 \mathrm{C} 6$ & Novocastra, Newcastle, UK & $\begin{array}{l}\text { Citrate } 10 \mathrm{mM} \mathrm{pH} \text { 6.5/Novolink } \\
\text { (Novocastra) }\end{array}$ & $1 / 10$ \\
\hline BCL6 & GI191E/A8 & CNIO, Madrid, Spain & $\begin{array}{l}\text { Citrate } 10 \mathrm{mM} \text { pH } 6.5 \text { and } \\
\text { proteinase K/Novolink (Novocastra) }\end{array}$ & $1 / 4$ \\
\hline FOXP1 & JC12 & CNIO, Madrid, Spain & $\begin{array}{l}\text { Citrate } 10 \mathrm{mM} \text { pH } 6.5 / \text { Novolink } \\
\text { (Novocastra) }\end{array}$ & $1 / 100$ \\
\hline CD30 & 6D/H2 & CNIO, Madrid, Spain & Citrate $10 \mathrm{mM}$ pH 6.5/FLEX (DAKO) & $1 / 1$ \\
\hline CD15 & 153B/D6/A2 & CNIO, Madrid, Spain & Citrate $10 \mathrm{mM}$ pH 6.5/FLEX (DAKO) & $1 / 2$ \\
\hline EBV-LMP1 & EBV-CS1-4 & Novocastra, Newcastle, UK & EDTA 1 mM pH 9/FLEX (DAKO) & $1 / 50$ \\
\hline p105/p50 & $\begin{array}{l}\text { Rabbit } \\
\text { polyclonal }\end{array}$ & Genetex, Irvine, CA, USA & Citrate $10 \mathrm{mM}$ pH 6.5/FLEX (DAKO) & $1 / 1$ \\
\hline p100/p52 & $\begin{array}{l}\text { Mouse } \\
\text { monoclonal }\end{array}$ & Millipore, Billerica, MA, USA & $\begin{array}{l}\text { Citrate } 10 \mathrm{mM} \text { pH } 6.5 \text { and } \\
\text { proteinase K/FLEX (DAKO) }\end{array}$ & $1 / 1000$ \\
\hline BCL2 & Clone 124 & DAKO, Glostrup, Denmark & Citrate $10 \mathrm{mM}$ pH 6.5/FLEX (DAKO) & $1 / 50$ \\
\hline $\mathrm{Ki}-67$ & MIB-1 & DAKO, Glostrup, Denmark & Citrate $10 \mathrm{mM}$ pH 6.5/FLEX (DAKO) & $1 / 100$ \\
\hline CD3 & F7.2.38 & DAKO, Glostrup, Denmark & EDTA 1 mM pH 9/FLEX (DAKO) & $1 / 200$ \\
\hline Карра & Карра & DAKO, Glostrup, Denmark & Citrate $10 \mathrm{mM}$ pH 6.5/FLEX (DAKO) & RTU \\
\hline Lambda & Lambda & DAKO, Glostrup, Denmark & Citrate $10 \mathrm{mM}$ pH 6.5/FLEX (DAKO) & RTU \\
\hline
\end{tabular}

Abbreviation: RTU, ready to use. 
EBV-Positive Diffuse Large B-Cell Lymphoma of the Elderly has a Post-Germinal Center Phenotypic Profile Related to Striking Nuclear Factor-kB Activation

Immunohistochemical evaluation (Table 3) showed all cases to be CD20 positive and commonly to coexpress CD30 (41/46, 89\%) and very rarely CD15 (4/43, 9\%). ISH for EBV (EBERs) revealed that all cases were positive, while all but seven cases tested were negative for EBV-LMP1. There was an $80 \%$ median percentage of EBER-positive cells in the

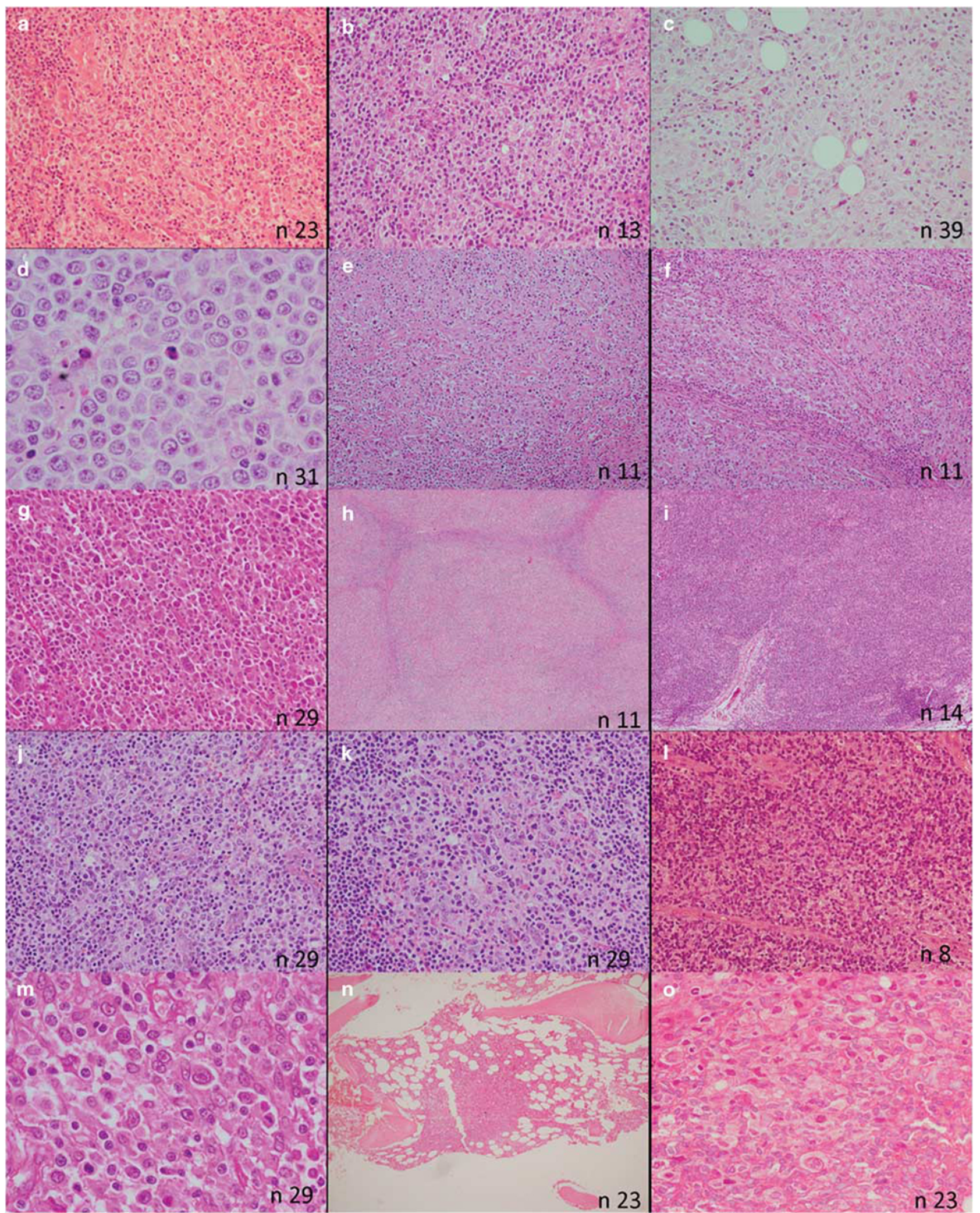


Table 3 Summary of major clinical features, histopathological features, immunohistochemical evaluation and COO subclassification of the series

\begin{tabular}{|c|c|c|c|}
\hline \multirow[t]{2}{*}{ Major clinical features } & & \multicolumn{2}{|c|}{ Immunohistochemical evaluation } \\
\hline & & IHQ marker & $\begin{array}{c}\text { No. of cases } \\
\text { positive/total no. of } \\
\text { cases }(\%)\end{array}$ \\
\hline Age (years) & Mean 69 (48-91) & & \\
\hline $\begin{array}{l}\text { Gender } \\
\text { Male } \\
\text { Female }\end{array}$ & $\begin{array}{l}31(66 \%) \\
16(34 \%)\end{array}$ & $\begin{array}{c}\text { CD20 } \\
\text { CD30 } \\
\text { CD15 } \\
\text { GCET1 }\end{array}$ & $\begin{array}{c}47 / 47(100 \%) \\
41 / 46(89 \%) \\
4 / 43(9 \%) \\
4 / 40(10 \%)\end{array}$ \\
\hline $\begin{array}{l}\text { Location } \\
\text { Nodal } \\
\text { Extranodal } \\
\text { Soft tissue } \\
\text { Spleen } \\
\text { Tonsil } \\
\text { Gastric } \\
\text { CNS } \\
\text { Large bowel } \\
\text { Liver } \\
\text { Nasal cavity }\end{array}$ & $\begin{array}{c}31(66 \%) \\
16(34 \%) \\
3 \\
3 \\
3 \\
3 \\
1 \\
1 \\
1 \\
1\end{array}$ & $\begin{array}{c}\text { CD10 } \\
\text { BCL6 } \\
\text { MUM1 } \\
\text { FOXP1 } \\
\text { BCL2 } \\
\text { Ki-67>50\% } \\
\text { EBV-LMP1 } \\
\text { EBER (ISH) }\end{array}$ & $\begin{array}{c}2 / 43(5 \%) \\
17 / 46(37 \%) \\
43 / 46(93 \%) \\
16 / 39(41 \%) \\
45 / 47(96 \%) \\
\\
40 / 45(84 \%) \\
\\
37 / 44(84 \%) \\
47 / 47(100 \%)\end{array}$ \\
\hline $\begin{array}{l}\text { Stage } \\
\text { I } \\
\text { II } \\
\text { III } \\
\text { IV } \\
\text { UNK }\end{array}$ & $\begin{array}{l}5(10.6 \%) \\
8(17 \%) \\
12(25.6 \%) \\
11(23.3 \%) \\
11\end{array}$ & $\begin{array}{c}\text { P50 } \\
\text { P52 } \\
\text { P50\&P52 }\end{array}$ & $\begin{array}{l}35 / 44(79 \%) \\
32 / 43(74 \%) \\
27 / 43(63 \%)\end{array}$ \\
\hline $\begin{array}{l}\text { Histopathological features } \\
\text { Polymorphic pattern (46 cases) } \\
\text { Large B-cell-type (29 cases, } 62 \% \text { ) } \\
\text { Polymorphic LPD-type (9 cases, 19\%) } \\
\text { Hodgkin-like type (8 cases, 17\%) } \\
\text { Monomorphic pattern ( } 1 \text { case) }\end{array}$ & & & \\
\hline
\end{tabular}

\begin{tabular}{lcc} 
COO classification & $\begin{array}{c}\text { EBV-positive DLBCL of the elderly } \\
\text { No. of cases positive/total no. of } \\
\text { cases (\%) }\end{array}$ & $\begin{array}{c}\text { EBV-negative DLBCL. } \\
\text { No. of cases positive } \\
\text { total no. of cases (\%) }\end{array}$ \\
\hline $\mathrm{GCB}^{\mathrm{b}}$ & $9 / 41(22 \%)$ & $128 / 324(39 \%)$ \\
$\mathrm{ABC}^{\mathrm{b}}$ & $32 / 41(78 \%)$ & $178 / 324(55 \%)$ \\
$\mathrm{GCB}^{\mathrm{c}}$ & $2 / 44(4 \%)$ & $116 / 324(35 \%)$ \\
Non-GC & $42 / 44(95 \%)$ & $188 / 324(58 \%)$
\end{tabular}

Abbreviations: ABC, activated B-cell-like type DLBCL; COO, cell of origin; GCB, germinal center B-cell-type DLBCL; non-GC, non-germinal center-type DLBCL.

${ }^{\mathrm{a}}$ Only nuclear localization of the staining is considered positive.

b According to Choi's algorithm.

${ }^{\mathrm{c}}$ According to Hans algorithm.

Figure 1 Pathological description of age-related Epstein-Barr virus (EBV)-positive diffuse large B-cell lymphoma. (a-c) Morphological features of large B-cell-type EBV-positive diffuse large B-cell lymphoma (a), polymorphic lymphoproliferative disorder-type (b) and Hodgkin-like type (c) EBV-positive diffuse large B-cell lymphoma of the elderly. (d) Pure immunoblastic monomorphic morphology was found in a single case, whereas areas showing a transition from monomorphic to polymorphic areas were not uncommon (g). (e and $\mathbf{f}$ ) One case displayed intermediate features between large B-cell-type (f) and Hodgkin lymphoma-like (e) tumors. (h and i) A nodular growth pattern was a prominent feature in $62 \%$ of the cases, with one case showing a striking nodular lymphocyte predominant Hodgkinlike morphology (i). (j) An evident degree of immunoblastic and plasmacytoid differentiation was found in large B-cell-type and polymorphic lymphoproliferative disorder-like cases. (k) The presence of germinal center-like structures was a peculiar feature in $23 \%$ of cases. Note the cellular composition with large blasts, follicular dendritic cells and small lymphocytes. (l) The non-neoplastic infiltrate was mainly composed of small lymphocytes and plasma cells in variable proportions. (m) Detailed cytology of large B-cell-type tumors revealed a dense large-cell population with immunoblastic morphology and a spectrum of plasmacytoid differentiation. (n and o) Bone marrow was examined in two cases that had multifocal interstitial infiltration by a polymorphic Hodgkin-like neoplastic population. 
population (10-100\%). In 45 out of 47 cases (96\%), we found overexpression of the antiapoptotic protein BCL2. A proliferative index $>50 \%$ of the cells, as measured by Ki-67 staining, was found in $84 \%$ of the cases (Figure 2).

When we grouped the cases according to the $\mathrm{COO}$ classification, ${ }^{15}$ using the immunohistochemical algorithms of Hans and Choi, ${ }^{16,17}$ we observed that most of the cases belonged to the non-germinal center/activated B-cell category (95\% non-germinal Center, according to the Hans algorithm; 78\% activated B cell, according to the Choi algorithm). This shift to a non-germinal center phenotype in age-related EBV-positive diffuse large B-cell lymphoma cases was confirmed when the COO distributions were compared with those of an EBVnegative diffuse large B-cell lymphoma control series (240 patients). With both classification systems, a greater than expected proportion of nongerminal center/activated B-cell cases was found in EBV-positive diffuse large B-cell lymphoma when compared with conventional EBV-negative diffuse large B-cell lymphoma ( $\chi^{2}$ test: $P<0.05$ ) (Table 3 ).

As the induction of an activated B-cell phenotype has been associated with nuclear factor- $k B$ pathway activation in diffuse large B-cell lymphoma, ${ }^{25,26}$ we measured the expression of two nuclear factor- $\mathrm{kB}$ subunits, p105/p50 and p100/p52, by immunohistochemistry and immunoblotting. Nuclear staining for p105/p50 was found in 79\% of the cases and for p100/p52 in $74 \%$ of the cases. In $63 \%$ of the cases evaluated (27/43), the two proteins were coexpressed in a nuclear location, which is indirect evidence of the activation of both classical and alternative nuclear factor-kB pathways (Figure 2 and Table 4). The frequency of nuclear factor- $k B$ pathway activation is higher than that observed in EBVnegative diffuse large B-cell lymphomas. We found a higher proportion of cases expressing either p105/ p50, p100/p52 or both proteins in age-related EBVpositive diffuse large B-cell lymphomas than in EBV-negative diffuse large B-cell lymphoma cases ( $\chi^{2}$ test: $P<0.001$ for all comparisons). This overexpression of nuclear factor-kB-related proteins was also greater than that expected in the analysis of solely the activated B-cell-type diffuse large B-cell lymphoma cases ( $\chi^{2}$ test: $P<0.001$ for all comparisons) (Table 4). Furthermore, this overexpression in age-related EBV-positive diffuse large B-cell lymphomas was found in germinal center B-type and activated B-cell-type diffuse large B-cell lymphomas, as classified by Choi's algorithm $\left(\chi^{2}\right.$ test for difference in expression of p105/p50, p100/p52 or both proteins between germinal center $\mathrm{B}$ and activated B-cell cases: $P=$ not significant in all comparisons), indicating that EBV may play an additional role in the overactivation of nuclear factor-kB pathways in EBV-positive diffuse large B-cell lymphomas, independently of the COO.

Further immunoblot experiments confirmed the expression of nuclear factor-kB subunits in EBV- positive diffuse large B-cell lymphoma primary samples. As shown in Figure 2, we found higher ratios of p50/p105 in EBV-positive diffuse large B-cell lymphoma samples than in EBV-negative diffuse large B-cell lymphoma control cases, indicating a highly active processing of the classical nuclear factor-kB pathway protein p105 to p50. We also found active processing of the alternative nuclear factor-kB pathway protein p100 to p52.

Thus, age-related EBV-positive diffuse large B-cell lymphomas display a striking shift to an activated B-cell phenotype, and nuclear expression of both classical and alternative nuclear factor- $k B$ subunits, p105/p50 and p100/p52. Active processing of these proteins is revealed by western blot in these cases. As this activation of the pathway is stronger than that in activated B-cell-type EBV-negative diffuse large B-cell lymphomas, EBV infection may play a direct and additional role in nuclear factor$\mathrm{kB}$ pathway 'superactivation'. Interestingly, this nuclear factor- $k B$ pathway activation is common to germinal center B- and activated B-cell-type EBVpositive diffuse large B-cell lymphomas.

\section{EBV-Positive Diffuse Large B-Cell Lymphoma of the Elderly Show Infrequent Translocations in IgH, $C-M Y C$ and BCL6 Locus}

After FISH analysis, 27 cases were evaluable for cytogenetic alterations in $C-M Y C, B C L 6$ and/or BCL2 locus. Regarding $C-M Y C$ locus, we found a single case with a positive split signal and two cases with more than three copies of the gene (gain). In all, 20 tested additional cases showed a normal double fusion pattern with BA probes. BCL2 was found to be gained in 3 out of 21 cases evaluable, and none case had BCL2 rearrangement. BCL6 gene was the gene most frequently altered in this series. Two out of 22 cases evaluable showed a pattern consistent with rearrangement of the gene and additionally 9 cases showed either a gain of BCL6 (although trisomy 3 cannot be ruled out in these cases). Three out of 27 cases evaluable had a rearrangement of $\operatorname{IgH}$ locus.

In summary, translocations involving IgH, C-MYC and BCL6 were rarely found in this series of EBV-positive diffuse large B-cell lymphomas of the elderly (5 out of 27 cases evaluable, 18\%). Interestingly, one case showed both $\operatorname{IgH}$ and $B C L 6$ rearrangements. However, gains in BCL6 locus/ trisomy 3 were commonly found ( $40 \%$ of the evaluable cases).

\section{EBV-Positive Diffuse Large B-Cell Lymphoma of the Elderly Is a Clonal B-Cell Neoplasm that Shows Frequently Associated Clonal T-Cell Populations}

Clonality assays using standardized primers and methods (Biomed $2^{20}$ ) was successfully performed in 41 cases using DNA extracted from formalin-fixed 


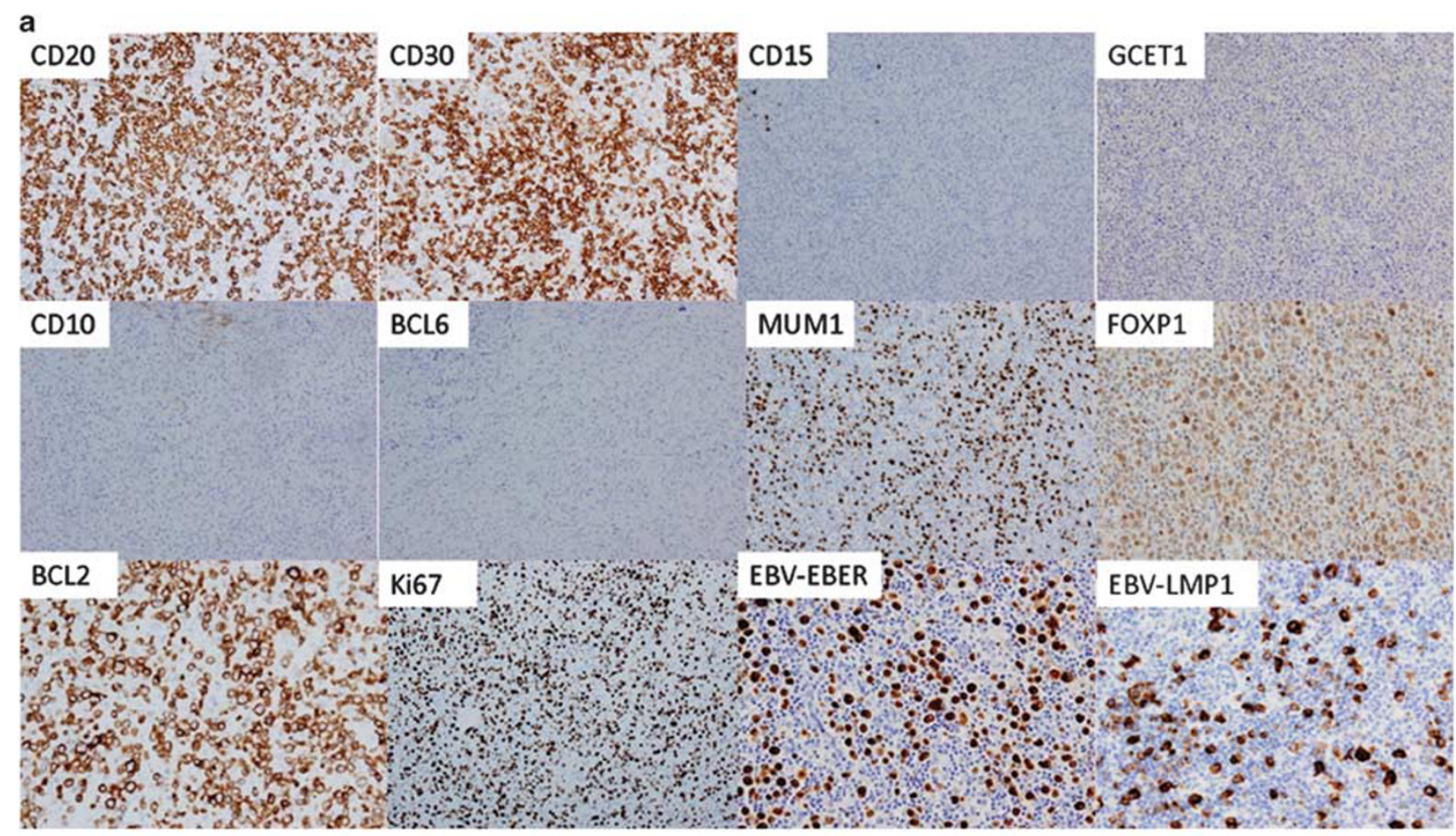

b

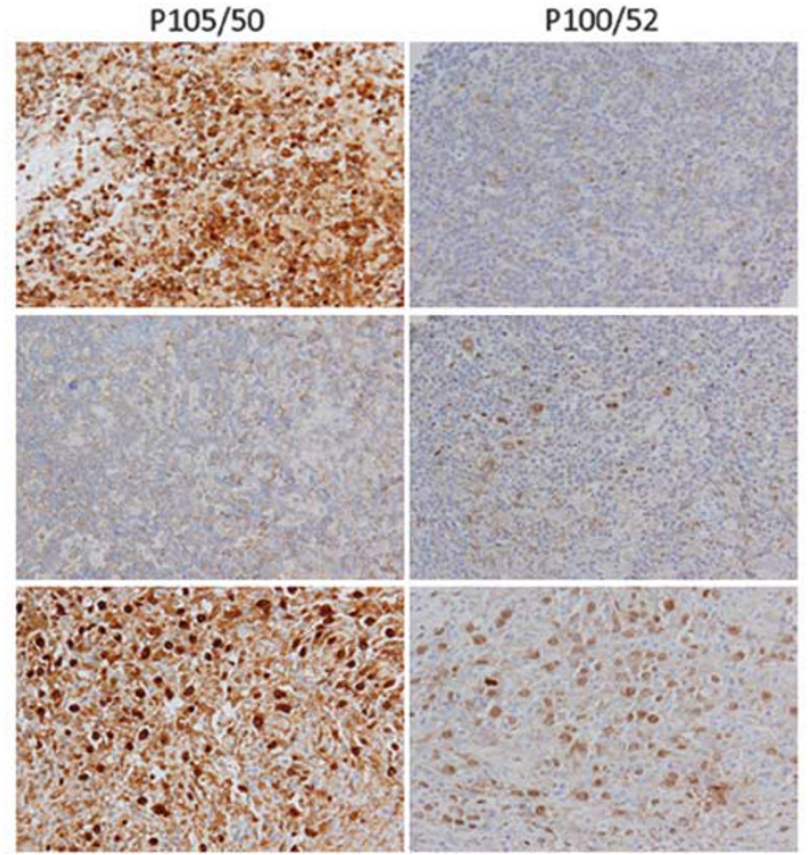

c

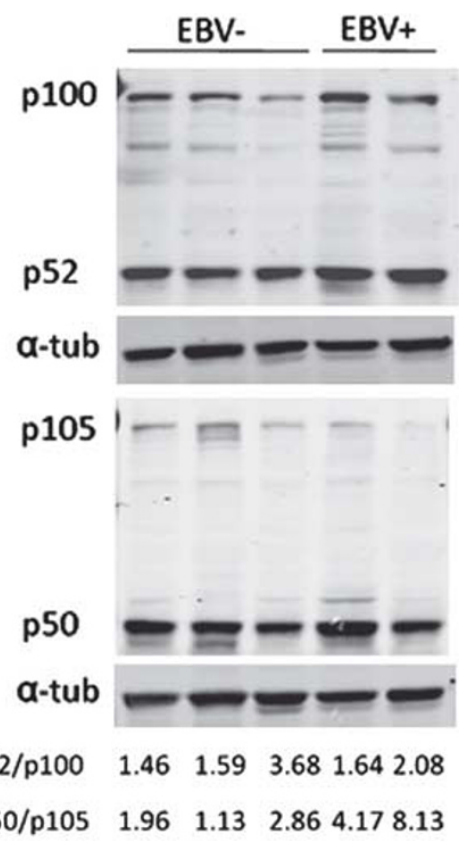

Figure 2 Age-related Epstein-Barr virus (EBV)-positive diffuse large B-cell lymphoma had a non-germinal center phenotypic profile with prominent nuclear factor-kB activation and BCL2 overexpression. (a) Typical immunohistochemical profile of EBV-positive diffuse large B-cell lymphoma of the elderly with moderate-intense expression of CD20 in most of the neoplastic population. Coexpression of CD30 was common. The tumors showed the absence of germinal center markers (CD10, BCL6 and GCET1) and positivity for MUM1 and FOXP1. The antiapoptotic protein BCL2 was overexpressed in 96\% of cases. A proliferative index higher than $50 \%$ of the cells, as measured by Ki-67, was found in $84 \%$ of the cases (details in Table 4). In situ hybridization for EBV (EBERs) showed all cases to be positive, while all but 7 cases tested were negative for EBV-LMP1. The median percentage of EBER-positive cells was 80\%. Note that both EBV-EBER and EBVLMP1 were expressed in large- and intermediate-sized cells. Note also that the percentage of EBV-LMP1-positive cells was lower than that of EBER-positive cells in paired cases. (b) Nuclear factor-kB pathway proteins (p105/p50 and p100/p52) were overexpressed in a nuclear location in most cases of EBV-positive diffuse large B-cell lymphoma of the elderly. Nuclear expression was taken as indirect evidence of both classical (p50) and alternative nuclear factor-kB (p52) pathway activity. (c) Immunoblot experiments confirmed the greater degree of processing of nuclear factor-kB-related proteins in EBV-positive diffuse large B-cell lymphoma primary samples. Activation of the pathway leads to degradation of p105 and p100 and, in turn, increased expression of p50 and p52, respectively. Increased active processing of mainly classical (p105/p50) but also alternative (p100/p52) nuclear factor-kB pathways occurred in EBV-positive diffuse large B-cell lymphomas compared with EBV-negative diffuse large B-cell lymphoma primary samples. 
Table 4 NF-kB pathway activation in EBV-positive DLBCL of the (a) elderly vs EBV-negative DLBCL; (b) elderly vs EBV-DLBCL (only ABC type cases)

\begin{tabular}{|c|c|c|c|}
\hline & No & Yes & Total \\
\hline \multicolumn{4}{|l|}{ (a) } \\
\hline \multicolumn{4}{|l|}{ Np52 } \\
\hline \multicolumn{4}{|l|}{ Series } \\
\hline EBV-positive DLBCL of the elderly & 11 & 32 & 43 \\
\hline EBV-negative DLBCL & 180 & 79 & 259 \\
\hline Total & 191 & 111 & 302 \\
\hline Pearson's $\chi^{2}$ & & $<0.001$ & \\
\hline \multicolumn{4}{|l|}{ Np50 } \\
\hline \multicolumn{4}{|l|}{ Series } \\
\hline EBV-positive DLBCL of the elderly & 9 & 35 & 44 \\
\hline EBV-negative DLBCL & 201 & 78 & 279 \\
\hline Total & 210 & 113 & 323 \\
\hline Pearson's $\chi^{2}$ & & $<0.001$ & \\
\hline \multicolumn{4}{|l|}{ Np50 and Np52 } \\
\hline \multicolumn{4}{|l|}{ Series } \\
\hline EBV-positive DLBCL of the elderly & 17 & 27 & 44 \\
\hline EBV-negative DLBCL & 180 & 20 & 200 \\
\hline Total & 197 & 47 & 244 \\
\hline Pearson's $\chi^{2}$ & & $<0.001$ & \\
\hline \multicolumn{4}{|l|}{ (b) } \\
\hline \multicolumn{4}{|l|}{ Np52 } \\
\hline \multicolumn{4}{|l|}{ Series } \\
\hline EBV-positive DLBCL of the elderly & 7 & 25 & 32 \\
\hline EBV-negative DLBCL & 105 & 44 & 149 \\
\hline Total & 112 & 69 & 181 \\
\hline Pearson's $\chi^{2}$ & & $<0.001$ & \\
\hline \multicolumn{4}{|l|}{ Np50 } \\
\hline \multicolumn{4}{|l|}{ Series } \\
\hline EBV-positive DLBCL of the elderly & 6 & 26 & 32 \\
\hline EBV-negative DLBCL & 117 & 54 & 171 \\
\hline Total & 123 & 80 & 203 \\
\hline Pearson's $\chi^{2}$ & & $<0.001$ & \\
\hline \multicolumn{4}{|l|}{ Np50 and Np52 } \\
\hline \multicolumn{4}{|l|}{ Series } \\
\hline EBV-positive DLBCL of the elderly & 10 & 22 & 32 \\
\hline EBV-negative DLBCL & 105 & 15 & 120 \\
\hline Total & 115 & 37 & 152 \\
\hline Pearson's $\chi^{2}$ & & $<0.001$ & \\
\hline
\end{tabular}

Abbreviations: DLBCL, diffuse large B-cell lymphoma; NF-kB, nuclear factor-kB; Np52, nuclear immunohistochemical expression of p100/ p52; Np50, nuclear immunohistochemical expression of p100/p52; ABC, activated B-cell-like type DLBCL.

EBV-positive DLBCL of the elderly shows a striking NF-kB activation when compared with EBV-negative DLBCL.

The frequency of NF-kB pathway activation is higher in EBV-positive DLBCL of the elderly than that observed in EBV-negative DLBCLs. We found a higher proportion of cases expressing either nuclear p105/p50, nuclear p100/p52 or both proteins in age-related EBVpositive DLBCLs than in EBV-negative DLBCL cases $\left(\chi^{2}\right.$ test: $P<0.001$ for all comparisons; Table 2a). This overexpression of NFkB-related proteins was also greater than expected in the analysis of solely the ABC DLBCL cases $\left(\chi^{2}\right.$ test: $P<0.001$ for all comparisons; Table 2b).

paraffin-embedded tissue. The DNA was not of sufficient quantity or quality $(\leq 200 \mathrm{bp}$ ) in six cases. Results are summarized in Table 5. Overall, 30 of 47 (64\%) cases clearly demonstrated $\mathrm{IgH}$ and/or $\mathrm{K} / \mathrm{Kde} /$ $L$ monoclonal rearrangements. IgH was monoclonal in 24 of 47 cases $(51 \%)$. Using a combination of $\mathrm{Vk}-$ $\mathrm{Jk}$ and $\mathrm{Vk} /$ intron-Kde primers, we found 23/47 monoclonal rearrangements $(57 \%)$. IgL clonal rearrangements were found in $3 / 17(17 \%)$ cases tested. One case showed IgL rearrangements in the absence of any IgK rearrangement.

We found a relatively high incidence of clonal TCR- $\gamma$ gene locus results: $10(24 \%)$ cases were monoclonal in at least one TCR- $\gamma$ gene tube; 2 cases were monoclonal in both TCR $\gamma$ tubes. We did not find any cases with clonal TCR- $\beta$ gene locus rearrangements. Thus, clonal T-cell populations appear to be common in age-related EBV-positive diffuse large B-cell lymphoma.

These results are in keeping with those of previous reports of monoclonal/oligoclonal T-cell expansions in patients with EBV-related disorders, including infectious mononucleosis ${ }^{27,28}$ and post-transplant lymphoproliferative disorders. ${ }^{29}$ It is likely that these monoclonal populations reflect the physiological T-cell response to EBV infection ('restricted T-cell repertoire').1,6,27,30 Knowledge of these common findings (clonal T-cell populations in EBV-positive diffuse large B-cell lymphoma) is useful to avoid the misdiagnosis of T-cell-associated malignancy.

\section{EBV-Positive Diffuse Large B-Cell Lymphoma of the Elderly is an Aggressive Neoplasm with Poor OS and PFS Compared with EBV-Negative Diffuse Large B-Cell Lymphoma}

A summary of the clinical features of the series can be found in Table 3 . We included 47 cases with a mean age of 69 years (range, 48-91 years). There was a predominance of men (31 male/16 female, ratio approximately 2:1). Most patients presented with nodal-based disease (31 cases, 66\%), while extranodal onset was found in 16 patients $(34 \%)$. The most frequent extranodal locations were soft tissue, spleen, tonsil and stomach. After staging procedures, half of the patients presented with advanced disease (stages III and IV in 49\% of patients). After application of the International Prognostic Index score that includes age, LDH level, stage, performance status and number of extranodal locations, ${ }^{31}$ patients were classified as low risk (IPI $0-1,7$ patients), lowintermediate risk (IPI 2, 12 patients), high-intermediate risk (IPI 3, 8 patients) or high risk (IPI 4-5; 8 patients).

Most patients with available information were treated with R-CHOP or R-CHOP-like regimens (20 patients). Other regimens were used (including ABVD, R-MegaCHOP, BAM-BCNU-MTX-ARAC and radiotherapy) in 14 patients. Two patients were not treated because they died before treatment. After treatment, 13 patients had no response or progression $(27 \%)$ and 19 achieved response (17 cases with complete remission and 2 patients with partial remission). Three out of $7(42 \%)$ patients treated with ABVD were alive at the moment of last follow- 


\begin{tabular}{|c|c|c|c|c|c|c|c|c|c|c|c|c|c|c|c|c|c|}
\hline \multirow[t]{3}{*}{$\begin{array}{l}\text { Case } \\
\text { no. }\end{array}$} & \multirow[t]{3}{*}{$\begin{array}{l}\text { Growth } \\
\text { pattern }^{\mathrm{a}}\end{array}$} & \multicolumn{2}{|c|}{$\begin{array}{c}C O O \\
\text { classification }\end{array}$} & \multicolumn{2}{|c|}{$\begin{array}{c}N F-k B \\
\text { activation }\end{array}$} & \multirow{3}{*}{$D N A Q$} & \multicolumn{10}{|c|}{$\begin{array}{l}\text { Clonality } \\
\text { analysis }\end{array}$} & \\
\hline & & \multirow[t]{2}{*}{$G C-A B C^{b}$} & \multirow[t]{2}{*}{$G C$-non- $G C^{\mathrm{c}}$} & \multirow[t]{2}{*}{$P 52^{\mathrm{d}}$} & \multirow[t]{2}{*}{$P 50^{\circ}$} & & \multicolumn{3}{|c|}{ IGH tubes } & \multicolumn{3}{|c|}{ IGK and IgL tubes } & \multicolumn{4}{|c|}{ TCR tubes } & \\
\hline & & & & & & & FR1 & $F R 2$ & FR3 & $I G K$ & IGKd & $\operatorname{Ig} L$ & $G-A$ & $G-B$ & $B-A$ & $B-B$ & \\
\hline 1 & LBC & $\mathrm{ABC}$ & Non-GC & Pos & Pos & 400 & MC (319bp) & PL & NC & PL & MC (162 bp) & - & PL & PL & PL & PL & \\
\hline 2 & PLPD & - & Non-GC & - & - & 400 & NC & $\mathrm{NC}$ & $\mathrm{NC}$ & NC & MC (138bp) & - & NC & NC & NC & $\mathrm{NC}$ & \\
\hline 3 & LBC & $\mathrm{ABC}$ & Non-GC & Pos & Pos & $300 / 0$ & NC & PL & PL & - & - & - & PL & PL & PL & PL & \\
\hline 4 & LBC & GCB & GCB & Neg & Pos & 0 & - & - & - & - & - & - & - & - & - & - & \\
\hline 5 & LBC & GCB & Non-GC & Pos & Pos & 400 & MC (319bp) & PL & MC (148bp) & - & - & - & PL & PL & PL & PL & \\
\hline 6 & PLPD & $\mathrm{ABC}$ & Non-GC & Pos & Pos & 0 & - & - & - & - & - & - & - & - & - & - & \\
\hline 7 & LBC & GCB & Non-GC & Pos & Pos & $300 / 100$ & PL & PL & PL & $\begin{array}{c}\text { MC (232, } \\
281 \mathrm{bp})\end{array}$ & PL & - & PL & PL & PL & $\mathrm{PL}$ & \\
\hline 8 & PLPD & - & Non-GC & - & - & - & - & - & - & - & - & - & - & - & - & - & \\
\hline 9 & LBC & $\mathrm{ABC}$ & Non-GC & $\mathrm{Neg}$ & Neg & $400 / 300$ & MC (345 bp) & PL & MC (105 bp) & PL & MC (148 bp) & - & PL & MC (192 bp) & PL & PL & \\
\hline 10 & LBC & $\mathrm{ABC}$ & Non-GC & Pos & Pos & 300 & - & MC (237 bp) & PL & PL & MC (269 bp) & - & PL & MC (207bp) & PL & PL & \\
\hline 11 & $\begin{array}{l}\text { LBC-HL- } \\
\text { like }\end{array}$ & $\mathrm{ABC}$ & Non-GC & Pos & Pos & $400 / 300$ & NC & NC & NC & NC & NC & - & $\mathrm{PL}$ & PL & PL & $\mathrm{PL}$ & \\
\hline 12 & LBC & GCB & Non-GC & Pos & $\mathrm{Neg}$ & 100 & $\mathrm{NC}$ & PL & PL & $\mathrm{NC}$ & NC & - & - & - & - & - & \\
\hline 13 & PLPD & $\mathrm{ABC}$ & Non-GC & Neg & Pos & 0 & - & - & - & - & - & - & - & - & - & - & \\
\hline 14 & $\begin{array}{l}\text { LBC (NLP- } \\
\text { like) }\end{array}$ & $\mathrm{ABC}$ & Non-GC & Pos & Pos & 400 & PL & PL & PL & PL & MC (269 bp) & - & PL & PL & PL & PL & \\
\hline 15 & LBC & $\mathrm{ABC}$ & Non-GC & Pos & Pos & $400 / 300$ & MC (312 bp) & MC (248 bp) & MC (104 bp) & PL & MC (269bp) & - & $\begin{array}{l}\text { MC (181, } \\
241 \text { bp) }\end{array}$ & PL & PL & PL & \\
\hline 16 & HL-like & $\mathrm{ABC}$ & Non-GC & Pos & Pos & - & - & PL & PL & PL & PL & - & PL & PL & PL & PL & \\
\hline 17 & LBC & - & - & - & Pos & 300 & PL & PL & MC (126bp) & PL & PL & PL & PL & PL & PL & PL & \\
\hline 18 & LBC & $\mathrm{ABC}$ & Non-GC & Pos & Pos & 300 & - & $\mathrm{NC}$ & MC (143 bp) & - & MC (131 bp) & - & PL & PL & PL & PL & \\
\hline 19 & LBC & $\mathrm{ABC}$ & Non-GC & $\mathrm{Neg}$ & Pos & 400 & MC (340 bp) & - & MC (139 bp) & PL & $\begin{array}{l}\text { MC (148bp, } \\
150 \mathrm{bp})\end{array}$ & PL & PL & PL & PL & PL & 古|圆 \\
\hline 20 & HL-like & GCB & GCB & Pos & $\mathrm{Neg}$ & 400 & PL & NC & MC (124 bp) & PL & MC (283 bp) & PL & PL & PL & PL & PL & 产| \\
\hline 21 & LBC & $\mathrm{ABC}$ & Non-GC & Neg & Neg & $0 / 400$ & PL & MC (282 bp) & MC (148 bp) & PL & $\begin{array}{c}\text { MC } \\
\text { (269bp bp) }\end{array}$ & - & PL & MC (177 bp) & PL & PL & 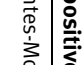 \\
\hline 22 & LBC & $\mathrm{ABC}$ & Non-GC & Pos & Pos & 400 & MC (317 bp) & MC (253 bp) & MC (127 bp) & PL & MC (291 bp) & MC (150 bp) & PL & PL & - & PL & $\frac{\overrightarrow{0}}{0}$ \\
\hline 23 & LBC & GCB & Non-GC & Pos & Pos & 400 & NC & MC (284 bp) & NC & PL & MC (269 bp) & - & PL & PL & PL & PL & $\stackrel{0}{0}$ \\
\hline 24 & LBC & $\mathrm{ABC}$ & Non-GC & Neg & Pos & 400 & MC (315 bp) & NC & MC (115 bp) & MC (238 bp) & PL & PL & PL & PL & PL & PL & \begin{tabular}{l|l}
$\circ$ \\
0
\end{tabular} \\
\hline 25 & HL-like & $\mathrm{ABC}$ & Non-GC & Pos & $\mathrm{Neg}$ & $400 / 100$ & MC (322 bp) & MC (255 bp) & NC & PL & MC (282 bp) & - & PL & MC (175 bp) & PL & PL & $\begin{array}{l}0 \\
2\end{array}$ \\
\hline 26 & $\begin{array}{l}\text { HL-like } \\
\text { (MO) }\end{array}$ & $\mathrm{ABC}$ & Non-GC & Pos & Pos & 400 & - & - & - & - & - & - & MC (165 bp) & IRREG PL & PL & PL & 옿 \\
\hline 27 & LBC & $\mathrm{ABC}$ & Non-GC & Pos & Pos & - & - & - & - & - & - & - & - & - & - & - & \\
\hline 28 & $\begin{array}{l}\text { HL-like } \\
\text { (MO) }\end{array}$ & - & - & - & - & - & - & - & - & - & - & - & - & - & - & - & \\
\hline 29 & LBC & $\mathrm{ABC}$ & Non-GC & Pos & $\mathrm{Neg}$ & 400 & $\begin{array}{c}\text { MC (335, } \\
340 \text { bp) }\end{array}$ & $\begin{array}{c}\text { MC (270, } \\
273 \text { bp) }\end{array}$ & $\begin{array}{c}\text { MC (129, } \\
139 \text { bp) }\end{array}$ & MC (236 bp) & PL & - & PL & PL & PL & $\mathrm{PL}$ & \\
\hline 30 & PLPD & $\mathrm{ABC}$ & Non-GC & Neg & $\mathrm{Neg}$ & 400 & MC (357 bp) & MC (282 bp) & $\mathrm{MC}(157 \mathrm{bp})$ & $\begin{array}{c}\text { MC (232, } \\
281 \text { bp) }\end{array}$ & MC (289 bp) & MC (139 bp) & PL & PL & PL & $\mathrm{PL}$ & \\
\hline 31 & $\begin{array}{l}\text { Monomor- } \\
\text { phic LBC }\end{array}$ & - & Non-GC & Neg & $\mathrm{Neg}$ & 400 & $\begin{array}{c}\text { MC (313, } \\
323 \text { bp) }\end{array}$ & MC (247 bp) & MC (148bp) & PL & PL & MC (152 bp) & $\mathrm{PL}$ & PL & PL & $\mathrm{PL}$ & \\
\hline 32 & LBC & $\mathrm{ABC}$ & Non-GC & Pos & Pos & 400 & MC (325 bp) & MC (282 bp) & MC (148bp) & PL & MC (269 bp) & - & PL & PL & PL & PL & \\
\hline 33 & PLPD & - & - & $\mathrm{Neg}$ & Pos & 400 & - & - & - & - & MC (269 bp) & - & NC & NC & NC & NC & \\
\hline 34 & PLPD & $\mathrm{ABC}$ & Non-GC & $\mathrm{Neg}$ & Pos & 400 & PL & PL & PL & PL & PL & PL & PL & PL & PL & PL & \\
\hline 35 & PLPD & GCB & Non-GC & Pos & Pos & $400 / 300$ & - & MC (282p) & $\begin{array}{c}\text { MC (110,1 } \\
32 \text { bp) }\end{array}$ & - & - & - & PL & PL & PL & PL & \\
\hline 36 & LBC & GCB & Non-GC & Pos & Pos & 400 & PL & PL & $\mathrm{PL}$ & MC (198 bp) & PL & PL & PL & PL & PL & PL & \\
\hline 37 & LBC & $\mathrm{ABC}$ & Non-GC & Pos & Pos & $100 / 0$ & - & MC (282 bp) & MC (148 bp) & - & - & - & $\mathrm{PL}$ & PL & PL & $\mathrm{PL}$ & \\
\hline 38 & LBC & $\mathrm{ABC}$ & Non-GC & Pos & Pos & $300 / 100$ & - & PL & PL & - & - & - & PL & MC (183 bp) & - & $\mathrm{PL}$ & \\
\hline 39 & HL-like & GCB & Non-GC & Neg & Pos & 400 & PL & MC (284 bp) & $\mathrm{MC}(148 \mathrm{bp})$ & - & MC (268 bp) & - & PL & PL & PL & PL & \\
\hline 40 & LBC & $\mathrm{ABC}$ & Non-GC & Pos & Pos & 400 & MC (331 bp) & MC (259 bp) & MC (111 bp) & - & PL & - & PL & MC (110bp) & PL & PL & \\
\hline 41 & PLPD & $\mathrm{ABC}$ & Non-GC & Pos & Pos & 400 & - & - & - & - & - & - & PL & PL & PL & PL & \\
\hline
\end{tabular}




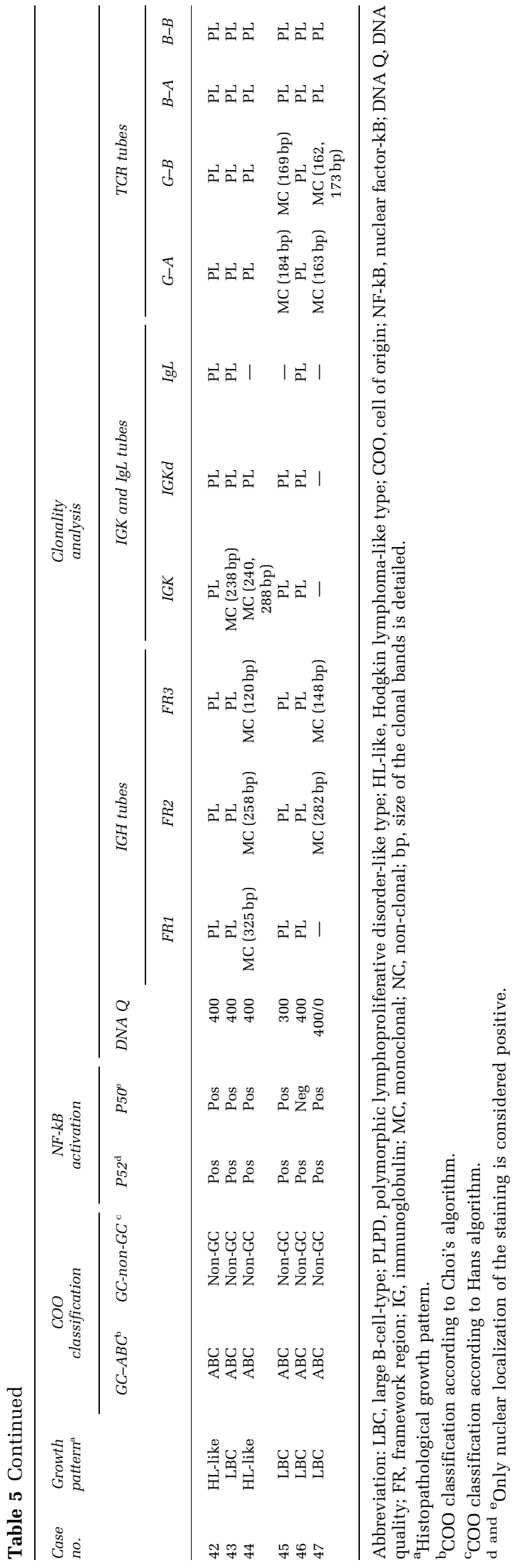

up. Out of $20(60 \%)$ patients, 12 treated with $\mathrm{R}-\mathrm{CHOP}$ and R-CHOP-like regimens remained alive at the moment of last follow-up. However, differences in log-rank tests for survival distributions were not significant according to treatment received nor the morphological pattern (data not shown).

The median follow-up time for all cases with available data (38 patients) was 9 months. The median follow-up among patients alive at last follow-up was 13 months. Out of 38 patients, 18 with available data died. Of these, 5 cases died of causes other than lymphoma (mainly pneumonia (4 cases) and sepsis (one case)), while 7 cases died of lymphoma. In 6 cases, the cause of death was not documented. The estimated 2-year OS was $40 \pm 10 \%$ and the estimated 2-year PFS was $36 \pm 9 \%$.

As activated B-cell phenotype and age are wellestablished factors related to poor outcome in diffuse large B-cell lymphoma cases, ${ }^{15-17,31}$ we compared the survival distributions of our EBVpositive diffuse large B-cell lymphoma cases and the control cohort of cases either after selection of activated B-cell subtype cases and/or patients older than 60 years of age. Age-related EBV-positive diffuse large B-cell lymphoma behaved worse than both activated B-cell-type EBV-negative diffuse large B-cell lymphoma and EBV-negative diffuse large B-cell lymphoma in older patients. These patients also have poorer OS and PFS than activated B-celltype EBV-negative diffuse large B-cell lymphoma older patients (log-rank test: $P<0.001$ ) (Figure 3). We should note that both age and activated B-cell subtype were of prognostic value in the EBVnegative diffuse large B-cell lymphoma cohort. ${ }^{18}$

\section{Discussion}

Age-related EBV-positive diffuse large B-cell lymphoma has recently been considered a provisional entity among diffuse large B-cell lymphoma subtypes. $^{32}$ It was initially described as 'senile EBVassociated B-cell lymphoproliferative disorder' ${ }^{3}$ in eastern populations, but little information was subsequently gathered from western populations. ${ }^{1,7}$ In recent years, it has been noted that defective immune surveillance for EBV may develop late in life and be associated with the development of EBVpositive B-cell lymphoproliferative disorder. ${ }^{1}$ This defective immune surveillance for EBV is associated with immunological deterioration as a result of aging $^{3-5}$ and explains the correlation between the increased incidence of this lymphoma type and the increased age of the patients found in the Eastern series. However, the definitional cutoff of 50 years proposed by the WHO is arbitrary, ${ }^{2,4}$ and cases below the age of 50 years can be found, provided an undiagnosed underlying immunodeficiency has been ruled out.

This emerging subtype of diffuse large B-cell lymphoma is characterized by its aggressive clinical 
a

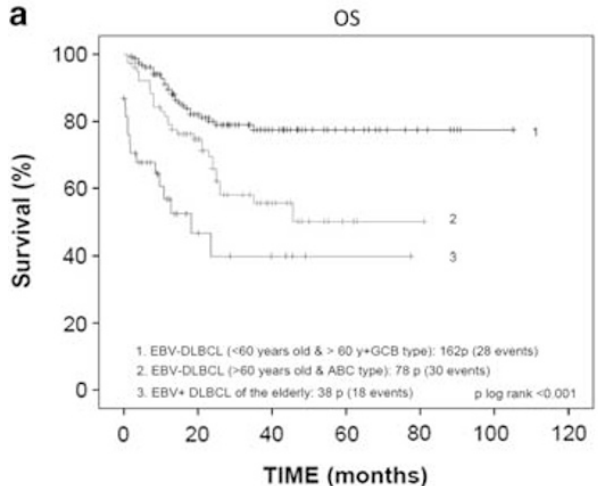

b

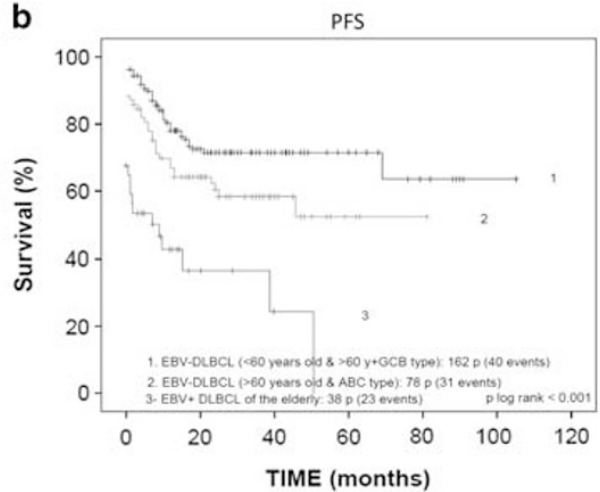

Figure 3 Epstein-Barr virus (EBV)-positive diffuse large B-cell lymphoma of the elderly is an aggressive neoplasm that had poor overall survival and progression-free survival when compared with EBV-negative diffuse large B-cell lymphoma. Kaplan-Meier plots of overall survival (a) and progression-free survival (b). The estimated 2-year overall survival was $40 \pm 10 \%$ and the estimated 2-year progressionfree survival was $36 \pm 9 \%$. Comparison with EBV-negative diffuse large B-cell lymphoma shows that EBV-positive diffuse large B-cell lymphoma behaved worse than both germinal center and activated B-cell-type diffuse large B-cell lymphomas (log-rank test: $P<0.001)$ and activated B-cell-type EBV-negative diffuse large B-cell lymphoma in older patients (log-rank test: $P<0.001$ ).

behavior and the higher risk of treatment failure than conventional EBV-negative diffuse large B-cell lymphoma ${ }^{8,14}$ or EBV-positive classical Hodgkin lymphoma in elderly patients. ${ }^{14}$ This aggressive behavior has been related mainly with the clinical features of the affected population, as a clear relationship between EBV positivity in diffuse large B-cell lymphoma and high-risk clinical features, such as advanced age, advanced stage, more than one extranodal involvement, high international prognostic index and presence of $\mathrm{B}$ symptoms has been demonstrated..$^{8,14}$

However, there is still very little information about the biological features of this neoplasm that can explain such aggressive behavior, or contribute to the identification of diagnostic markers or therapeutic targets for this particular subpopulation of high-risk patients. Here we demonstrate that age-related EBV-positive diffuse large B-cell lymphoma is an aggressive, clonal B-cell neoplasm with a striking nuclear factor-kB pathway activation in neoplastic cells. The increased activation of the pathway is related to EBV infection and appears in both activated B-cell and germinal center B-cell tumors.

Most of the cases collected here presented initially nodal involvement locations, although extranodal presentation has been described in previous series., ${ }^{3,13}$ Morphologically, these tumors showed a variety of patterns of growth and differentiation that needs to be recognized to allow a diagnosis of suspicion before confirmation with phenotypic studies. All but one case have a polymorphic histology, with a noticeable variability in cell size and differentiation found within the tumor. Among these polymorphic cases, both large B-cell and polymorphic lymphoproliferative disorder-like tumors showed a striking degree of immunoblastic/plasmacytoid differentiation that could be useful as a diagnostic clue. The single monomorphic case showed clearcut immunoblastic features, in line with all other cases. This degree of immunoblastic differentiation and prominent geographic necrosis have previously been described as common features, ${ }^{3,13,14}$ and can aid in the morphological recognition of the entity. More challenging is the differential diagnosis of Hodgkin lymphoma-like cases with EBV-positive classical Hodgkin lymphoma in elderly patients. Here we have used three simple criteria to classify the case as EBV-positive diffuse large B-cell lymphoma of the elderly instead of classical Hodgkin: (1) morphology consistent with a polymorphic lymphoproliferative disorder and higher large-cell density and degree of differentiation toward blasts than expected for classical Hodgkin lymphoma; (2) a high degree of expression of B-cell markers with moderate-intense positivity for $\mathrm{CD} 20$ in $>50 \%$ of the neoplastic population; and (3) positivity for EBV-EBER in largeand intermediate-sized cells. Clinical and phenotypic features have been described to be helpful in the recognition of this entity. Thus, the diagnosis of agerelated EBV-positive diffuse large B-cell lymphoma is favored in cases featuring geographical necrosis, a higher degree of expression of B-cell markers CD20 and CD79a, the presence of light-chain restriction, ${ }^{4,9}$ EBNA2 expression and a prominent cytotoxic T-cell inflammatory background. ${ }^{13}$ A particularly helpful additional feature of this lymphoma type, atypical in classical Hodgkin lymphoma, is the wide range of size of EBV-positive B cells, as highlighted by CD20 and EBER. We have used this finding as a valid diagnostic criterion, consistently with what has been described in other EBV-related B-cell lymphoproliferative disorders. ${ }^{33}$ CD15 positivity, which was for a long time considered to be a major discriminatory factor between EBV-positive diffuse large B-cell lymphoma and classical Hodgkin lymphoma, ${ }^{3,9,13}$ has recently been found in lesions other than classical Hodgkin lymphoma (particularly EBV-positive mucocutaneous ulcers ${ }^{33}$ ), suggesting that the presence or absence of CD15 should not be considered a determining factor in this differential diagnosis. 
Immunohistochemical and ISH studies enabled us to demonstrate that EBV is always found in a significant proportion of the neoplastic population (median of $80 \%$ of cells, as revealed by ISH). ISH for EBV and EBV-LMP1 are both suitable detection methods, but the former is more sensitive as EBVLMP1 is not always present and, when expressed, occurs in a lower percentage of cells (Figure 2). The tumors also have high proliferation rates and commonly overexpress the antiapoptotic protein BCL2. These are both features that could be partially related to its aggressive features, as they have also been associated with unfavorable outcome in classical series of conventional diffuse large B-cell lymphomas $^{34}$ and classical Hodgkin lymphomas. ${ }^{35}$

As COO differentiation into germinal center B-like and activated B-cell-like diffuse large B-cell lymphoma classification types is increasingly becoming accepted as a clinically useful classification system for diffuse large B-cell lymphomas for the purpose of prognosis ${ }^{15,16,36,37}$ and potentially for predicting better response to treatments with nuclear factor$\mathrm{kB}$ inhibitors, ${ }^{38}$ we studied the distribution of the two subtypes in EBV-positive diffuse large B-cell lymphoma of the elderly. We found that age-related EBV-positive diffuse large B-cell lymphomas display a striking shift to an activated B-cell phenotype.

A major finding of this study is the presence of an activation of classical and alternative nuclear factor$\mathrm{kB}$ pathways, as measured by nuclear accumulation and processing of the nuclear factor-kB-related proteins p105/p50 and p100/p52, in a large proportion of these cases, with a frequency higher than the observed in paired EBV-negative diffuse large B-cell lymphoma cases. Furthermore, although Choi's algorithm recognizes a higher proportion of germinal center B cases than does the Hans algorithm, both germinal center B- and activated B-cell-type EBVpositive diffuse large B-cell lymphomas feature this nuclear factor-kB pathway increased activation, which provides a biological rationale for the use of nuclear factor-kB inhibitors as alternative therapies. ${ }^{39}$

Thus, EBV infection might play a direct and additional role in nuclear factor-kB pathway activation. The relationship between EBV infection and nuclear factor-kB pathway activation is well established from experimental data showing that EBV can elicit nuclear factor-kB responses by mimicking BCR and CD40 signaling cascades, respectively, through the encoded proteins LMP2A ${ }^{40,41}$ and LMP1. ${ }^{42-45}$ Furthermore, expression of the EBV latent membrane protein 1 induces B-cell lymphoma in transgenic mice. ${ }^{46}$

Regarding the genetics of EBV-positive diffuse large B-cell lymphoma of the elderly, previous reports have found $\operatorname{IgH}$ translocations in $19 \%$ of the cases $^{47}$ and the $t(9 ; 14)(p 13 ; q 32)$ in a single case report. ${ }^{48}$ We have performed a detailed FISH analysis to screen for major translocations involving $I g H$, $C-M Y C, B C L 6$ and BCL2. Our results suggest that these common alterations in conventional diffuse large B-cell lymphoma are rarely found in EBVpositive diffuse large B-cell lymphoma of the elderly. Only $18 \%$ of the cases evaluated here show a translocation involving $\operatorname{IgH}$ (3 cases), $C-M Y C$ (1 case) or $B C L 6$ ( 2 cases). Although our analysis is restricted to single loci, our results fit with the presence of a lower number of genomic alterations in EBV-positive diffuse large B-cell lymphoma found by comparative genomic hybridization analysis in cases associated with other sources of immunosuppression (human immunodeficiency virus and post-transplant setting) by other groups. ${ }^{49-52}$ Thus, our results are in line with the concept that both immunosuppression and EBV oncogenic effects in concert may reduce the need of additional chromosomal alterations frequently found in conventional EBV-negative diffuse large B-cell lymphoma.

In summary, we show that EBV-positive diffuse large B-cell lymphoma of the elderly is an aggressive, clonal B-cell neoplasm with prominent nuclear factor-kB pathway activation in the neoplastic cells. Morphological features are helpful for raising suspicion of a diagnosis that can be confirmed after demonstrating EBV infection and a characteristic phenotype. Clonality testing confirms the B-cell monoclonal nature of the process in most cases and frequently demonstrates clonal T-cell populations of uncertain significance. Knowledge of these common findings is useful to avoid misdiagnosis of associated T-cell malignancy. These tumors behave aggressively and have poor OS and PFS with conventional treatments.

Thus, alternative therapies based on the tumor biology (ie, prominent nuclear factor-kB activation) need to be tested under controlled clinical trials in patients with age-related EBV-positive diffuse large B-cell lymphoma.

\section{Acknowledgements}

This study was supported by grants from the Asociación Española contra el Cancer (AECC) and the Ministerio de Ciencia e Innovación (RTICC, SAF 2008-03871), Spain. We thank Laura Cereceda and CNIO's Tumour Bank Unit (MJ Artiga and Manuel Morente) for their skilful retrieval and handling of clinical data and samples from different clinical institutions. We also acknowledge all the clinical colleagues who kindly completed the clinical data form.

\section{Disclosure/conflict of interest}

The authors declare no conflict of interest.

\section{References}

1 Cohen JI, Kimura H, Nakamura S, et al. Epstein-Barr virus-associated lymphoproliferative disease in nonimmunocompromised hosts: a status report and sum- 
mary of an international meeting, 8-9 September 2008. Ann Oncol 2009;20:1472-1482.

2 Nakamura SJE, Swerdlow SH. EBV Positive Diffuse Large B-Cell Lymphoma of the Elderly, WHO Classification of Tumours of Haematopoietic and Lymphoid Tissues. IARC Press: Lyon, 2008.

3 Oyama T, Ichimura K, Suzuki R, et al. Senile EBV+ Bcell lymphoproliferative disorders: a clinicopathologic study of 22 patients. Am J Surg Pathol 2003;27:16-26.

4 Shimoyama Y, Yamamoto K, Asano N, et al. Age-related Epstein-Barr virus-associated B-cell lymphoproliferative disorders: special references to lymphomas surrounding this newly recognized clinicopathologic disease. Cancer Sci 2008;99:1085-1091.

5 Shimoyama Y, Oyama T, Asano N, et al. Senile Epstein-Barr virus-associated B-cell lymphoproliferative disorders: a mini review. J Clin Exp Hematop 2006; 46:1-4.

6 Bharadwaj M, Burrows SR, Burrows JM, et al. Longitudinal dynamics of antigen-specific CD8+ cytotoxic T lymphocytes following primary Epstein-Barr virus infection. Blood 2001;98:2588-2589.

7 Schrager JPS, Rafled M, Jaffe ES. EBV reactivation syndromes in adults without known immunodeficiency. Mod Pathol 2009;22(Suppl 1):285A.

8 Park S, Lee J, Ko YH, et al. The impact of Epstein-Barr virus status on clinical outcome in diffuse large B-cell lymphoma. Blood 2007;110:972-978.

9 Oyama T, Yamamoto K, Asano N, et al. Age-related EBV-associated B-cell lymphoproliferative disorders constitute a distinct clinicopathologic group: a study of 96 patients. Clin Cancer Res 2007;13:5124-5132.

10 Gibson SE, Hsi ED. Espstein-Barr virus-positive B-cell lymphoma of the elderly at a United States tertiary medical center: an uncommon aggressive lymphoma with a nongerminal center B-cell phenotype. Hum Pathol 2009;40:653-661.

11 Dojcinov SD, Venkataraman G, Pittaluga S, et al. Age related EBV associated lymphoproliferative disordera spectrum of reactive lymphoid hyperplasia and lymphoma: the Western experience. Blood 2011;117: 4726-4735.

12 Hofscheier APA, Bonzheim I, Adam P, et al. Geographic variation in the prevalence of Epstein-Barr virus-positive diffuse large B-cell lymphoma of the elderly: a comparative analysis of a Mexican and a German population. Mod Pathol 2011;24:1046-1054.

13 Asano N, Yamamoto K, Tamaru J, et al. Age-related Epstein-Barr virus (EBV)-associated B-cell lymphoproliferative disorders: comparison with EBV-positive classic Hodgkin lymphoma in elderly patients. Blood 2009;113:2629-2636.

14 Shimoyama Y, Asano N, Kojima M, et al. Age-related EBV-associated B-cell lymphoproliferative disorders: diagnostic approach to a newly recognized clinicopathological entity. Pathol Int 2009;59:835-843.

15 Alizadeh AA, Eisen MB, Davis RE, et al. Distinct types of diffuse large B-cell lymphoma identified by gene expression profiling. Nature 2000;403:503-511.

16 Choi WW, Weisenburger DD, Greiner TC, et al. A new immunostain algorithm classifies diffuse large B-cell lymphoma into molecular subtypes with high accuracy. Clin Cancer Res 2009;15:5494-5502.

17 Hans CP, Weisenburger DD, Greiner TC, et al. Confirmation of the molecular classification of diffuse large B-cell lymphoma by immunohistochemistry using a tissue microarray. Blood 2004;103:275-282.
18 Montes-Moreno S, Martinez N, Sanchez-Espiridión B, et al. miRNA expression in diffuse large B-cell lymphoma treated with chemoimmunotherapy. Blood 2011;118:1034-1040.

19 Kallioniemi OP, Wagner U, Kononen J, et al. Tissue microarray technology for high-throughput molecular profiling of cancer. Hum Mol Genet 2001;10: 657-662.

20 van Krieken JH, Langerak AW, Macintyre EA, et al. Improved reliability of lymphoma diagnostics via PCRbased clonality testing: report of the BIOMED-2 concerted action BHM4-CT98-3936. Leukemia 2007; 21:201-206.

21 Cheson BD, Pfistner B, Juweid ME, et al. Revised response criteria for malignant lymphoma. J Clin Oncol 2007;25:579-586.

22 Kaplan EMP. Nonparametric stimation from incomplete observations. Am Stat Assoc J 1958;53:457-481.

23 Peto R, Pike MC, Armitage P, et al. Design and analysis of randomized clinical trials requiring prolonged observation of each patient. I. Introduction and design. Br J Cancer 1976;34:585-612.

24 Quintanilla-Martinez L, de Jong D, de Mascarel A, et al. Gray zones around diffuse large B cell lymphoma. Conclusions based on the workshop of the XIV meeting of the European Association for Hematopathology and the Society of Hematopathology in Bordeaux, France. J Hematop 2009;2:211-236.

25 Compagno M, Lim WK, Grunn A, et al. Mutations of multiple genes cause deregulation of NF-kappaB in diffuse large B-cell lymphoma. Nature 2009;459: 717-721.

26 Davis RE, Brown KD, Siebenlist U, et al. Constitutive nuclear factor kappaB activity is required for survival of activated B cell-like diffuse large B cell lymphoma cells. J Exp Med 2001;194:1861-1874.

27 Callan MF, Steven N, Krausa P, et al. Large clonal expansions of CD8+ $\mathrm{T}$ cells in acute infectious mononucleosis. Nat Med 1996;2:906-911.

28 Krafft AE, Taubenberger JK, Sheng ZM, et al. Enhanced sensitivity with a novel TCRgamma PCR assay for clonality studies in 569 formalin-fixed, paraffin-embedded (FFPE) cases. Mol Diagn 1999;4:119-133.

29 Ibrahim HA, Menasce LP, Pomplun S, et al. Presence of monoclonal T-cell populations in B-cell post-transplant lymphoproliferative disorders. Mod Pathol 2011;24:232-240.

30 Plumbley JA, Fan H, Eagan PA, et al. Lymphoid tissues from patients with infectious mononucleosis lack monoclonal B and T cells. J Mol Diagn 2002;4: 37-43.

31 Project TIN-HsLPF. A predictive model for aggressive non-Hodgkin's lymphoma. The International NonHodgkin's Lymphoma Prognostic Factors Project. N Engl J Med 1993;329:987-994.

32 Swerdlow SH, Harris NL, Jaffe ES, et al. WHO Classification of Tumours of Haematopoietic and Lymphoid Tissues. IARC Press: Lyon, 2008.

33 Dojcinov SD, Venkataraman G, Raffeld M, et al. EBV positive mucocutaneous ulcer-a study of 26 cases associated with various sources of immunosuppression. Am J Surg Pathol 2010;34:405-417.

34 Lossos IS, Morgensztern D. Prognostic biomarkers in diffuse large B-cell lymphoma. J Clin Oncol 2006;24: 995-1007.

35 Rassidakis GZ, Medeiros LJ, Vassilakopoulos TP, et al. BCL-2 expression in Hodgkin and Reed-Sternberg 
cells of classical Hodgkin disease predicts a poorer prognosis in patients treated with ABVD or equivalent regimens. Blood 2002;100:3935-3941.

36 Meyer PN, Fu K, Greiner TC, et al. Immunohistochemical methods for predicting cell of origin and survival in patients with diffuse large B-cell lymphoma treated with rituximab. J Clin Oncol 2011;29:200-207.

37 Wright G, Tan B, Rosenwald A, et al. A gene expression-based method to diagnose clinically distinct subgroups of diffuse large B cell lymphoma. Proc Natl Acad Sci USA 2003;100:9991-9996.

38 Dunleavy K, Pittaluga S, Czuczman MS, et al. Differential efficacy of bortezomib plus chemotherapy within molecular subtypes of diffuse large B-cell lymphoma. Blood 2009;113:6069-6076.

39 Staudt LM. Oncogenic activation of NF-kappaB. Cold Spring Harb Perspect Biol 2010;2:a000109.

40 Kuppers R. B cells under influence: transformation of B cells by Epstein-Barr virus. Nat Rev Immunol 2003; 3:801-812.

41 Mancao C, Hammerschmidt W. Epstein-Barr virus latent membrane protein $2 \mathrm{~A}$ is a B-cell receptor mimic and essential for B-cell survival. Blood 2007;110: 3715-3721.

42 Mosialos G, Birkenbach M, Yalamanchili R, et al. The Epstein-Barr virus transforming protein LMP1 engages signaling proteins for the tumor necrosis factor receptor family. Cell 1995;80:389-399.

43 Brown KD, Hostager BS, Bishop GA. Differential signaling and tumor necrosis factor receptor-associated factor (TRAF) degradation mediated by CD40 and the Epstein-Barr virus oncoprotein latent membrane protein 1 (LMP1). J Exp Med 2001;193:943-954.
44 Thornburg NJ, Kulwichit W, Edwards RH, et al. LMP1 signaling and activation of NF-kappaB in LMP1 transgenic mice. Oncogene 2006;25:288-297.

45 Uchida J, Yasui T, Takaoka-Shichijo Y, et al. Mimicry of CD40 signals by Epstein-Barr virus LMP1 in B lymphocyte responses. Science 1999;286:300-303.

46 Kulwichit W, Edwards RH, Davenport EM, et al. Expression of the Epstein-Barr virus latent membrane protein 1 induces B cell lymphoma in transgenic mice. Proc Natl Acad Sci USA 1998;95:11963-11968.

47 Dojcinov SD, Venkataraman G, Pittaluga S, et al. Agerelated EBV-associated lymphoproliferative disorders in the Western population: a spectrum of reactive lymphoid hyperplasia and lymphoma. Blood 2011; 117:4726-4735.

48 Ohno H, Nishikori M, Haga $\mathrm{H}$, et al. Epstein-Barr virus-positive diffuse large B-cell lymphoma carrying a $\mathrm{t}(9 ; 14)(\mathrm{p} 13 ; \mathrm{q} 32)$ translocation. Int J Hematol 2009;89: 704-708.

49 Capello D, Scandurra M, Poretti G, et al. Genome wide DNA-profiling of HIV-related B-cell lymphomas. Br J Haematol 2010;148:245-255.

50 Kwee I, Capello D, Rinaldi A, et al. Genomic aberrations affecting the outcome of immunodeficiencyrelated diffuse large B-cell lymphomas. Leuk Lymphoma 2011;53:71-76.

51 Rinaldi A, Kwee I, Poretti G, et al. Comparative genome-wide profiling of post-transplant lymphoproliferative disorders and diffuse large B-cell lymphomas. Br J Haematol 2006;134:27-36.

52 Vaghefi P, Martin A, Prévot S, et al. Genomic imbalances in AIDS-related lymphomas: relation with tumoral Epstein-Barr virus status. AIDS 2006;20:2285-2291.

Supplementary Information accompanies the paper on Modern Pathology website (http://www.nature.com/ modpathol) 